\title{
GAGASAN KONSENTRASI PEMBIDANGAN \\ JURUSAN PENDIDIKAN AGAMA ISLAM FAKULTAS \\ TARBIYAH \\ (By Using Separated-Subject Matter Curriculum Approach)
}

\author{
Ahmad Muthohar \\ Dosen Tetap Jurusan PAI Fakultas Tarbiyah IAIN Walisongo Semarang
}

\begin{abstract}
In general, curriculum materials in the fields of PAI includes four categories, namely 1) the materials associated with the alQuran and al-Hadith, 2) materials relating to faith and morality, 3) material related to fiqh, and 4) materials relating to the history of Islam. The fact shows that the various departments and institutions is not specified into the fields. This paper will outline the concept of specified in PAI Department in accordance with the approach to the majors Separated-Subject Matter Curriculum planning which will result in five divisions material into five PAI study program, those are program of study: 1) Islamic Education (PAI), which prepare students to become a teacher of Islamic religion in school, 2) The course of study the Quran, Hadith, 3) The course of study Aqidah Akhlaq, 4) Fiqh Study Program, and 5) Program Cultural History of Islamic studies which prepare the students to be a teacher at the madrasah.

Keywords: Division Concentration, Islamic Religious Education, Separated-Subject Matter Curriculum Approach.
\end{abstract}

\section{Pendahuluan}

Fakultas Tarbiyah merupakan fakultas yang mempunyai missi untuk mencetak guru yang memiliki empat kompetensi, yakni kompetensi paedagogik, kompetensi kepribadian, kompetensi professional dan kompetensi sosial. (Depdiknas RI, 2006: 69). Missi ini dimaksudkan untuk melayani kebutuhan masyarakat akan guru pada tingkat pendidikan dasar dan menengah baik lembaga pendidikan yang bernaung di bawah Departemen Pendidikan Nasional maupun Departemen Agama. Untuk memenuhi kebutuhan ini Fakultas Tarbiyah sebagai lembaga pendidikan 


\section{Ahmad Muthohar}

tenaga kependidikan telah membekali mahasiswa dengan seperangkat ilmu yang terdiri atas ilmu agama Islam, ilmu bahasa, ilmu kependidikan dan keguruan, serta ilmu penunjang lainnya.

Salah satu program studi yang ditawarkan oleh Fakultas Tarbiyah adalah jurusan Pendidikan Agama Islam (PAI). yang bertujuan untuk mendidik mahasiswa yang dipersiapkan untuk menjadi guru agama Islam yang mampu menguasai materi-materi keagamaan maupun metodologi pembelajarannya. Secara umum materi-materi keagamaan ini telah terangkum dalam empat kategori, yakni 1) materi-materi yang berhubungan dengan al-Qur'an dan al-Hadits, 2) materi-materi yang berhubungan dengan keyakinan dan akhlaq, 3) materi-materi yang berhubungan dengan syari'ah dan fiqh dan 4) materi-materi yang berhubungan dengan sejarah keislaman. Empat kategori ini diklasifikasikan pada mata kuliah dasar umum (MKDU) yang harus diambil oleh seluruh mahasiswa PTAI dengan pengembangan yang disesuaikan dengan missi fakultas masingmasing. Sedangkan untuk keahlian dalam bidang paedagodik, mahasiswa jurusan Pendidikan Agama Islam (PAI) dibekali materi-materi yang berhubungan dengan ilmu keguruan dan kependidikan dengan tujuan setelah mereka menjadi guru nanti menunjukkan performance sebagai pendidik yang mempunyai kompetensi sebagaimana yang dipersyaratkan Undang-undang. Artinya mereka harus mampu 1) membuat perencanaan pembelajaran (lesson plan) materi yang akan disampaikan dengan segala langkah-langkahnya, 2) melaksanakan proses pembelajaran (learning process) dengan menggunakan metode, strategi, pendekatan, media dan alat bantu pembelajaran (learning aid) yang tepat, 3) mampu melakukan pengelolaan kelas (classroom management) dan 4) melaksanakan penilaian (assesement) sebagai ukuran keberhasilan atas dirinya sebagai guru dalam proses pembelajaran di kelas. Dengan bahasa lain, mereka diharapkan mampu melakukan pembelajaran yang efektif (Potter, 2000: 342) dalam praktik yang sesungguhnya dengan mempertimbangkan gaya belajar peserta didik (Nasution, 2003: 1994).

Dengan dibekali kemampuan penguasaan materi dan kemampuan mengaplikasikan metodologi sebagaimana disebutkan di atas, mereka diharapkan siap pakai untuk menjadi guru yang mengajarkan mata pelajaran Pendidikan Agama Islam di lembaga pendidikan baik sekolah 
atau madrasah. PAI sebagai sebuah mata pelajaran merupakan bagian tak terpisahkan dari kurikulum suatu sekolah atau madrasah sehingga merupakan alat untuk mencapai salah satu aspek kompetensi tamatan sekolah atau madrasah bersangkutan. Secara khusus PAI ini didesain dan diberikan siswa yang beragama Islam dalam rangka meningkatkan keberagamaan mereka. (Pasal 37 ayat 1 Undang-Undang Nomor 20 tahun 2003). Dengan fungsi ini PAI diharapkan dapat mengantarkan peserta didik memiliki karakteristik 'sosok muslim yang diidealkan, yakni memiliki tingkat keberagamaan tertentu.

Melihat harapan fungsi PAI sedemikian rupa, maka Jurusan PAI sebagai producer guru-guru Pendidikan Agama Islam (PAI) yang melayani di sekolah dan madrasah, haruslah mempersiapkan mahasiswa sebaik mungkin agar dapat melayani masyarakat dengan baik. Untuk kasus pelayanan di madrasah ada sinyalemen bahwa alumni jurusan PAI belumlah memenuhi kompetensi yang standardized dengan adanya indikasi banyaknya keluhan dari madrasah pengguna alumni Jurusan PAI yang dapat disimpulkan bahwa para alumni kurang menguasai materi dan metodologi pembelajaran bagi masing-masing mata pelajaran dalam rumpun kurikulum PAI. (Hasil wawancara Hasil dengan beberapa kepala madrasah pengguna alumni Jurusan PAI pada tahun 2006 di Jepara). Hal ini disinyalir karena mahasiswa tidak dibekali dengan materi-materi terkait serta metodologi pembelajarannya. Terkait dengan ini, kiranya perlu ditempuh kebijakan baru untuk mencari solusi alternatif dengan menerapkan separated subject matter curriculum approach pada materi-materi Ilmu Agama Islam sesuai dengan tuntutan mata pelajaran di madrasah. Sehingga perlu mata kuliah tambahan sebagai pilihan wajib (compulsory elective subject) yang diambil oleh seluruh mahasiswa Jurusan PAI. Mata kuliah ini berupa Pendidikan Al-Qur'an-Hadits, Pendidikan Aqidah-Akhlaq, Pendidikan Fiqih dan Pendidikan Sejarah Kebudayaan Islam.

\section{Separate Subject-Matter Curriculum Sebagai Pendekatan}

Separated subject-matter curriculum merupakan organisasi dari sebuah kurikulum. Agar tidak terjadi kesalahan dalam memahami hal tersebut perlu kirannya dijelaskan tentang kurikulum. Istilah kurikulum berasal dari bahasa Yunani yang terdiri dari kata curri yang berarti "pelari" 
dan curre yang berarti "tempat berpacu" sehingga curriculum diartikan " jarak yang harus ditempuh oleh seorang pelari”. Berdasarkan makna tadi, pada awalnya kurikulum dalam dunia pendidikan diartikan sebagai kumpulan mata pelajaran yang harus ditempuh oleh peserta didik guna memperoleh ijazah atau menyelesaikan pendidikannya (Hamalik, 2001: 16).

Dalam perkembangannya, pengertian kurikulum tersebut dipandang sangat sempit karena hanya menekankan dua hal pokok yaitu: isi kurikulum berupa kumpulan mata pelajaran (subject matter) yang diberikan sekolah kepada peserta didik dan tujuan pendidikan atau kurikulum, agar peserta didik menguasai mata pelajaran tadi yang disimpulkan dalam bentuk ijazah atau sertifikat. Syalor dan Alexander mendefinisikan kurikulum dengan: the school curriculum is the total effort of the school to bring about desired outcome in school an in-out- of school situation. In short, the curriculum is the school program for learners (Saylor \& Alexander, 1960: 4).

Pendapat Saylor dan Alexander tersebut tampaknya cenderung menempatkan kurikulum tidak hanya terbatas pada pengaturan dan penyusunan sejumlah mata pelajaran untuk diajarkan pada peserta didik, melainkan kurikulum itu juga termasuk semua upaya atau program lembaga pendidikan untuk mencapai tujuan pendidikan.

Sementara itu, Hilda Taba justru lebih mengutamakan program, planning atau strategi daripada pemberian sejumlah mata pelajaran kepada peserta didik, karena menurutnya "curriculum is a plan for learning" (Taba, 1962: 4). Di sini tampak bahwa kurikulum terfokus pada upaya mempersiapkan peserta didik untuk berpartisipasi sebagai salah satu unsur pendidikan yang proaktif dalam penataan proses pendidikan. Maka komponen kurikulum seperti tujuan pendidikan dan pembelajaran, metode dan evaluasi tetap masih perlu diperhatikan.

Mengenai kurikulum dan hal yang berkaitan dengan organisasi kurikulum para ahli pendidikan membagi menjadi tiga: yakni Separated Subject-Matter Curriculum, Correlated Curriculum dan Integrated Curriculum ( Nasution, 1989: 23) yang masing-masing mempunyai karakteristik yang berbeda. Dalam Separated Subject Matter Curriculum mata kuliah tidak dipusatkan pada suatu masalah atau topik tertentu, tidak seperti Integrated Curriculum di mana semua bidang studi dirancang dengan mengacu pada topik tertentu (Nurdin dkk, 2004: 49). Apa yang 
disajikan dalam mata kuliah -meskipun mata kuliah tersebut dengan lainnya serumpun - haruslah berbeda antara satu dengan lainnya. Misalnya Ilmu Agama Islam bisa dibedakan menjadi mata kuliah Ulum al-Qur'an, Tafsir, Ulum al-Hadits, Hadits, Fiqh, Ushul Fiqh, Ilmu Kalam dan lain-lain. Padahal ilmu-ilmu tersebut bisa menjadi satu mata kuliah Agama Islam. Model penyajian kurikulum seperti disebut Separated Subject Curriculum, karena segala materi perkuliahan disajikan dalam subject atau mata kuliah yang terpisah-pisah, yang satu lepas dari yang lain (Nasution, 2003: 178). Subject atau mata kuliah ini merupakan hasil pengalaman umat manusia sepanjang masa atau kebudayaan dan pengetahuan yang dikumpulkan oleh umat manusia sejak dulu kala. Bahan ini lalu disusun logis, sistematis serta disederhanakan dan disesuaikan dengan usia dan kematangan peserta didik (Nasution, 2003: 178).

Kelebihan-Kelebihan Separated - Subject Matter Curikulum

- Bahan pelajaran dapat disampaikan secara logis dan sistematis.

Tiap mata kuliah mengandung sistematika tertentu. Ilmu Tauhid misalnya diawali dengan pembahasan rukun iman, al-ghaibat (iman kepada hal-hal ghaib) dan al-sam'iyat (iman kepada informasi yang dibawa oleh wahyu). Dalam ilmu fiqh dimulai dari thaharah sebelum membahas tentang ibadah shalat, zakat, pauasa dan ibadah-ibadah lainnya. Demikian dapat dilihat, bahwa setiap mata kuliah atau disiplin mempunyai sistematik tertentu. Dengan mengikuti sistematik itu mahasiswa terlatih berpikir menurut struktur disiplin, misalnya dengan mempelajari ilmu kalam, mahasiswa dapat berpikir secara sistematik dengan logika dan falsafah qur'ani di mana setiap cabang pengetahuan ini tidak akan dapat ditemukan peserta didik itu sendiri. Oleh sebab itu, jalan yang efisien ialah beri peserta didik ilmu pengetahuan itu dalam susunan yang logis seperti telah dipikirkan para pakar.

- Organisasi kurikulum mudah direncanakan dan dilaksanakan

Dari segala macam kurikulum, kurikulum inilah yang paling mudah disusun, direorganisasi, ditambah, atau dikurangi. Masalah scope dan sequence tidak terlalu menimbulkan kesulitan. Scope terutama soal menentukan jumlah dan jenis mata kuliah yang harus disajikan oleh perguruan tinggi. Sequence adalah soal menentukan urutan mata kuliah yang harus diberikan dalam tiap jenjang semester. Dalam menentukan 


\section{Ahmad Muthohar}

kurikulum ini banyak pula bantuan yang diperoleh dari buku-buku referensi yang telah diakui, sehingga lebih memudahkan cakupan (scope) dan urutan (sequence) bahan mata kuliah pada tiap kelas..

- Kurikulum ini mudah dinilai

Kurikulum ini terutama bertujuan menyampaikan sejumlah pengetahuan, pengertian, dan kecakapan-kecakapan tertentu yang mudah dinilai dengan ujian atau tes. Ada kalanya bahan pelajaran ditentukan dengan menetapkan buku-buku referens yang harus dikuasai untuk suatu daerah, bahkan untuk seluruh negara, sehingga dapat diadakan ujian umum yang uniform di seluruh negara (Nasution, 2003: 183).

- Kurikulum ini juga dipakai di pendidikan tinggi

Madrasah Ibtidaiyah masih dianggap oleh kebanyakan orang sebagai persiapan untuk madrasah Tsanawiyah dan madrasah Tsanawiyah sebagai sekolah persiapan untuk madrasah Aliyah dan madrasah Aliyah sebagai persiapan Pendidikan Tinggi. Boleh dikatakan, pada saat ini setiap perguruan tinggi menggunakan organisasi kurikulum yang bersifat matapelajaran yang terpisah-pisah. Kebanyakan orang tua menginginkan agar anak-anaknya kelak melanjutkan pelajarannya di fakultas pendidikan (tarbiyah). Karena ilu kurikulum yang berbentuk subject diterima baik dan dipertahankan di MI, MTs dan Madrasah Aliyah,

- Kurikulum ini teiah dipakai berabad-abad lamanya dan sudah menjadi tradisi

Kurikulum ini telah digunakan dan diterima baik oleh generasigenerasi yang lalu, sehingga mendapat dukungan dari orang tua dan para pengajar. Sukar orang mencrima perubahan dalam organisasi kurikulum yang telah bertahan begitu lama. Orang tua yang menginginkan anak-anaknya ke sekolah menganggap sewajarnya, bahwa anak itu mempelajari bermacam-macam mata pelajaran seperti yang mereka pelajari (Sujana, 1989: 56).

- Kurikulum ini lebih memudahkan dosen dan mudah diubah

Segala perubahan atau perbaikan kurikulum kita hingga saat ini senantiasa didasarkan pada organisasi berbentuk subject. Perubahan atau perbaikan kurikulum dicapai dengan menambah atau mengurangi jumlah, isi atau jenis matapelajaran sesuai dengan permintaan zaman. 
Kalau dirasa perlu Mahasiswa mengetahui tcntang fiqh yang lebih mumpuni, akhlaq tasawuf, tafsir dan lain-lain, maka matapelajaran itu mudah ditambahkan. Demikian pula matapelajaran yang dirasa tidak sesuai lagi, dapat ditiadakan (Sujana, 1989: 56).

- Organisasi kurikulum yang sistematis

Seperti yang dimiliki oleh subject-curriculum essensi untuk menafsirkan pengalaman, kurikulum ini sangat menghemat waktu, tenaga dan memberikan kemungkinan mempelajari sesuatu dalam waktu singkat apa yang ditemukan dengan susah payah oleh para sarjana pada masa lampau (Nasution, 1983: 194).

\section{Kekurangan-Kekurangan Separated- Subject Curriculum}

- Mata pelajaran yang lepas-lepas, tidak berhubungan satu dengan yang lain.

Kurikulum berbentuk mata kuliah yang terpisah-pisah tidak mendidik mahasiswa dapat menghadapi situasi-situasi dalam kehidupannya. Mata kuliah memberikan kepada mahasiswa sebuah pengetahuan yang lepas. Hal ini diperkuat lagi apabila tiap mata kuliah yang diberikan oleh dosen itu berlainan seperti halnya di Fakultas Tarbiyah Jurusan PAI konsetrasi pendidikan Fiqh tanpa mengetahui apa yang diberikan pada pelajaran lain karena setiap mata kuliah berdiri sendiri, dan mahasiswa disuruh mengumpulkan sejumlah pengetahuan yang lepaslepas.

- Tidak memperhatikan masalah-masalah sosial yang dihadapi anakanak.

Dalam prakteknya, kurikulum ini bertujuan menyampaikan sejumlah pengetahuan yang terdapat dalam buku-buku referensi yang ditentukan. Sering kali bahan perkuliahan itu tidak ada hubungannya dengan masalah-masalah yang dihadapi mahasiswa dalam kehidupannya. Misalnya mahasiswa sukar melihat tujuan pelajaran yang terpisahpisah itu. Mereka pada umumnya mempelajari dengan cara menghafal supaya mendapat nilai baik, atau menghindari kecaman dari dosen (Sukmadinata, 2000: 115).

- Menyampaikan pengalaman masa lampau yang sistematis dan logis.

Kurikulum ini banyak terdapat kekurangan di dalamnya jika ditinjau 


\section{Ahmad Muthohar}

dari sudut psikologi. Hal ini lebih-lebih berlaku bagi anak-anak Madrasah Ibtidaiyah dikarenakan mereka bertambah pengetahuannya berdasar pengalaman-pengalaman langsung yang berarti bagi dirinya karena hal itu bertalian dengan kehidupan dan kebutuhannya seharihari.

- Kurikulum kurang mengembangkan kemampuan berfikir.

Kurikulum ini mengutamakan penguasaan pengetahuan dengan jalan ulangan dan hafalan. dan kurang mengajak mahasiswa berpikir sendiri. Pertanyaan-pertanyaan dan soal-soal yang mereka hadapi telah mempunyai jawaban-jawaban tertentu, sehingga tidak ada kebebasan menemukan jawaban sendiri. Mahasiswa umumnya menerima segala sesuatu atas otoritas dosen atau buku referensi. Selain dari itu bahan perkuliahan biasanya lebih dahulu ditetapkan secara "otoktratis" oleh pihak atasan. Mahasiswa tidak diturutsertakan dalam merencanakan dan membicarakan apa yang akan dipelajari seperti halnya dalam pengajaran unit (Sujana, 1989: 57).

- Kurikulum lebih cenderung menjadi statis dan ketinggalan zaman.

Bahan perkuliahan dalam kurikulum ini terutama didasarkan pada pengetahuan yang telah tercantum dalam buku. Adakalanya suatu buku digunakan dari tahun ke tahun tanpa perubahan dan penyesuaian dengan keadaan masyarakat yang dinarnis yang terus-menerus berkembang dengan pesatnya. Itu sebabnya maka perkuliahan di pendidikan tinggi sering ketinggalan zaman. Apa yang benar pada suatu saat mungkin tidak sesuai lagi pada zaman yang berikutnya. Dalam pengajaran proyek mahasiswa menghadapi masalah-masalah yang aktual dengan menggunakan bahan dari sumber-sumber yang up-todate. Pada zaman global dan internet ini mahasiswa masih mempelajari teori-teori lama yang tidak terpakai lagi, karena berpegang pada kurikulum yang subject-centered.

Meskipun separate subject Matter curriculum ini banyak diserang dari berbagai pihak, tetapi sekalipun tidak ada tokoh atau aliran tertentu yang mempertahankannya, namun bentuk kurikulum ini masih hidup dengan subur di mana-mana. Hal ini tidak mengherankan, karena kebaikannya, sedangkan alternatif yang diberikan, seperti misalnya integrated curriculum 
sangat banyak menimbulkan kesulitan dalam penerapannya oleh dosen dalam perkuliahan.

\section{Konsentrasi Pembidangan}

Seperti diketahui bahwa pengguna lulusan Jurusan PAI adalah lembaga pendidikan sekolah dan madrasah. Bagi lulusan Jurusan PAI yang mengajar di sekolah mungkin cukup dibekali dengan materi-materi ilmu Agama Islam yang bernaung pada kategori Mata Kuliah Dasar (MKD), namun bagi yang mengajar di madrasah, lulusan ini tidak cukup hanya dibekali dengan MKD. Mereka harus dibekali secara khusus tentang materi-materi yang berkaitan dengan mata pelajaran al-Qur'an-hadits, Aqidah-Akhlaq, Fiqh dan Sejarah kebudayaan Islam yang diajarkan di madrasah. Yang dimaksud dengan pembekalan ini meliputi perencanaan pembelajarannya, proses pembelajarannya, pengelolaaan kelas dan cara menilai setelah pembelajaran berlangsung. Masing-masing mata pelajaran tersebut mempunyai kerakteristik tersendiri dalam metode penyampaiannya.

Sehubungan dengan itu, sebenarnya gagasan konsentrasi pembidangan ini berawal dari keluhan-keluhan masyarakat pengguna yang berasal dari madrasah. Mereka kurang puas atas kompetensi para alumni yang kurang menguasai bidang materi keislaman. Mereka dianggap kurang qualified dibandingkan dengan alumni UIN, IAIN dan STAIN dari fakultas lainnya, misalnya fakultas Syari'ah dalam penguasaan materi Fiqh dan alQur'an-Hadits, fakultas Ushuluddin dalam penguasaan Aqidah-Akhlaq dan fakultas Adab dalam penguasaan Sejarah Kebudayaan Islam.

Dari latar belakang tersebut, maka Jurusan Pendidikan Agama Islam (PAI) seyogyanga menempuh kebijakan dengan membentuk program studi-program studi baru sesuai dengan kurikulum sebagai mata pelajaran di sekolah dan madrasah. Kalau di sekolah hanya ada mata pelajaran PAI, sementara di madrasah ada mata pelajaran Al-qur'an-Hadits, Aqidah Akhlaq, Fiqh dan Sejarah Kebudayaan Islam, maka program studi yang dibuka adalah program studi: 1) Pendidikan Agama Islam (PAI), yang dipersiapkan untuk menjadi guru agam Islam di sekolah, 2) Program studi Al-qur'an-Hadits, 3) Program studi Aqidah Akhlaq, 4) Program studi Fiqh dan 5) Program studi Sejarah Kebudayaan Islam, yang dipersipakan untuk 
menjadi guru di madrasah.

Pada praktiknya mahasiswa kelima program studi ini tetap dibekali materi-materi Mata Kuliah Dasar (MKD) dan Mata Kuliah Utama (MKU) yang sama. Yang membedakan adalah materi-materi Mata Kuliah Pilihan (MKP). Pada mata kuliah pilihan masing program studi harus berbeda sesuai dengan pilihan mahasiswa yang berkehendak menjadi guru mata pelajaran tertentu. Misalnya mahasiswa hendak menjadi guru PAI di sekolah maka ia harus mengambil program studi PAI, kalau ia hemdak menjadi guru mata pelajaran Fiqh di madrasah maka ia harus mengambil program studi pendidikan Fiqh dan sebagainya.

Secara rinci, dapat dilihat tawaran penulis untuk konsentrasi pembidangan masing-masing program studi yang dapat dikembangkan dalam Jururan Pendidikan Agama Islam (PAI) antara lain:

1. Program Studi PAI

Untuk program studi ini mahasiswa cukup dibekali dengan seluruh Mata Kuliah Dasar (MKD) dan Mata Kuliah Utama (MKU) ditambah dengan beberapa mata kuliah pilihan lain sebagai penunjang seorang guru PAI di sekolah. Mereka yang mengambil program studi ini hanya dipersiapkan sebagai guru PAI di sekolah bukan di madrasah.

2. Program Studi Al-Qur'an-Hadits

Mahasiswa yang mengammbil program studi ini dipersiapkan sebagai guru mata pelajaran Al-qur'an-Hadits di madrasah. Mereka perlu dibekali mata kuliah-mata kuliah pilihan yang sesuai dengan kebutuhan mata pelajaran al-Qur'an-Hadits di madrasah.

Adapun Subject matetter curriculum Konsentrasi pendidikan Al Qur'an-Hadits meliputi; Ilmu Tajwid, Ilmu Tafsir, Ilmu Tilawah dan Qira'at, ayat Tarbawiyah, Ulum al-Hadits II, Telaah Kitab-kitab Hadits, Al-Qur'an dan Islam Kontenporer, Telaah Kurikulum Al-Qur'anHadits di Madrasah.

3. Program Studi Aqidah-Akhlaq

Mahasiswa yang mengammbil program studi ini dipersiapkan sebagai guru mata pelajaran Aqidah-Akhlaq di madrasah. Mereka perlu dibekali mata kuliah-mata kuliah pilihan yang sesuai dengan kebutuhan mata pelajaran Aqidah-Akhlaq di madrasah.

Adapun Subject matetter curriculum Konsentrasi pendidikan Aqidah 
Akhlaq meliputi; Filsafat Agama, Sejarah Perkembangan Pemikiran Islam Kontenporer, Tauhid II, Ilmu Kalam II, Akhlaq Tasawuf II, Sejarah Agama-agama, Teologi Islam dan Modernitas, Perbandingan Agama, metologi Pembelajaran Aqidah Akhlaq, Telaah Kurikulum Aqidah Akhlaq di Madrasah.

4. Program Studi Fiqh

Mahasiswa yang mengammbil program studi ini dipersiapkan sebagai guru mata pelajaran Fiqh di madrasah. Mereka perlu dibekali mata kuliah-mata kuliah pilihan yang sesuai dengan kebutuhan mata pelajaran Fiqh di madrasah.

Adapun Subject matetter curriculum pendidikan Fiqh meliputi; Fiqih Ibadah, Fiqih Mu'amalah, Fiqh Jinayah, Fiqh Ahwal Al-Syahsiyah, Fiqh Siyasah, Fiqih Kontemporer, Tharikh Tasyri', Qawaid al-Fiqiyah, Telaah Kurikulum Fiqh di Madrasah, Metodologi Pembelajaran Fiqih.

5. Program Studi Sejarah Kebudayaan Islam (SKI)

Mahasiswa yang mengammbil program studi ini dipersiapkan sebagai guru mata pelajaran Sejarah Kebudayaan Islam (SKI) di madrasah. Mereka perlu dibekali mata kuliah-mata kuliah pilihan yang sesuai dengan kebutuhan mata pelajaran Sejarah Kebudayaan Islam (SKI) di madrasah.

Adapun Subject matetter curriculum pendidikan Sejarah Kebudayaan Islam meliputi; Tipologi SKI, Filsafat Sejarah, Studi Tokoh, Studi Islam Kawasan, Geografi Islam, Sejarah Islam Kontemporer, Metodologi Penelitian Sejarah, Metodologi Pembelajaran SKI, Telaah Kurikulum SKI di Madrasah).

\section{Penutup}

Ada beberapa hal yang harus dipersiapkan untuk memenuhi pembukaan program-program studi baru di bawah naungan Jurusan PAI, terutama infrasturktur serta sumber daya manusia, yakni kesiapan dosendosen yang benar-benar menguasai di bidangnya. Sedangkan untuk memspesifikkan Jurusan ini maka perlu dibuka konsentrasi sesuai dengan bidang garapan disekolah yang dapat diajukan kedalam lima program studi yaitu program studi: 1) Pendidikan Agama Islam (PAI), yang dipersiapkan untuk menjadi guru agam Islam di sekolah, 2) Program studi 
Al-qur'an-Hadits, 3) Program studi Aqidah Akhlaq, 4) Program studi Fiqh dan 5) Program studi Sejarah Kebudayaan Islam, yang dipersipakan untuk menjadi guru di madrasah.

Kelima konsentrasi pembidangan di atas hanyalah tawaran penulis yang mungkin lebih realistis dalam melihat kebutuhan masyarakat pengguna. Dengan cara ini mudah-mudahan apa yang dibutuhkan oleh sekolah dan madrasah terpenuhi. Amin.

\section{Daftar Pustaka}

Undang-undang Republik Indonesia Nomor 14 Tahun 2005 Tentang Guru dan Dosen, (Jakarata: Depdiknas RI, 2006),

Booby de Potter, Quantum Teaching , (Birmingham: Routladge Press, 2000)

Nasution, Berbagai Pendekatan dalam Proses Belajar dan Mengajar, ( Jakarta : Bumi Aksara, 2003 )

Undang-Undang Nomor 20 tahun 2003 tentang sistem pendidikan nasional.

Oemar Hamalik, Kurikulum dan Pembelajaran, (Jakarta: Bumi Aksara, 2001)

Abdullah Idi, Pengembangan Kurikulum Teori dan Praktek, (Yogyakarta: Gaya Media Pratama, 1999)

J. Galen Saylor \& W.M. Alexander, Curriculum Planning for Better Teaching and Learning, (New York: Holt Renehart and Winston, 1960),

Hilda Taba, Curriculum Development Theories and Practice (New York: Harcourt, Brace and Word, 1962),

S. Nasution, Pengembangan Kurikulum, (Bandung: Sinar Baru, 1989),

H. Syafruddin Nurdin dkk, Guru Profesional dan Implementasi Kurikulum, (Jakarta: Ciputat Prsess, 2004)

S. Nasution, Asas-Asas Kurikulum,(Jakarta: Bumi Aksara, 2003)

Nana Sujana, Pembinaan dan Penyelenggaraan Kurikulum di Sekolah, (Bandung: Sinar Baru, 1989) 
Nana Syaodih Sukmadinata, Pengembangan Kurikulum, Teori dan Praktek, (Bandung: Remaja Rosdakarya, 2000),

Tim Fakultas Tarbiyah IAIN Walisongo, Profile Fakultas Tarbiyah, (Semarang: Tarbiyah Press, 2008)

Pusat Kurikulum, Standar Kompetensi Mata Pelajaran Pendidikan Agama Islam, (Jakarta: Balitbang Depdiknas, 2000)

W.S. Winkel, Psikologi Pendidikan dan Evaluasi Belajar, (Jakarta: PT. Gramedia, 1983)

Baron, Robert A. Psychology. (Boston: Allyn and Bacon, 1989)

Bobby de Potter, Quantum Teaching, (Birmingham: Routhladge Press, 2000) 